\title{
Semantic Features and the Distribution of Adverbs
}

\author{
Thomas Ernst \\ Indiana University \\ ternst@indiana.edu
}

\begin{abstract}
This paper proposes that we can predict which adverbs cannot adjoin to the right in headinitial languages by means of a particular semantic property, that of being a "subjective" adverb, one which maps an event or proposition onto a scale with the high degree of indeterminacy and context-dependence. Such adverbs, such as probably or luckily, cannot adjoin to the right with non-manner readings, while other adverbs (like politically, often, or deliberately) may. This supports the view that the distribution of adverbs depends heavily, and subtly, on their lexicosemantic properties.
\end{abstract}

\section{Introduction}

In this paper most of the discussion will be about lexical semantics, but still it is ultimately a syntax paper. My overall concern is to build a theory of adverb distribution that will tell us, for any given adverb in a language, where it can occur in a sentence, what possible meanings it can have in each position, and what other elements it can cooccur with. We want this theory not simply to make a list, but to make these predictions by means of general principles, and to do so in as restrictive a way as possible. And it is universally agreed that at least some aspects of the distribution of an adverb can be predicted by its lexical semantics. The goal of this paper is to identify a particular semantic property that correlates directly with one specific fact about adverbial distribution.

The major syntactic fact at issue is that some adverbs are able to adjoin to the right in VO languages while others cannot. (Throughout this paper I will ignore OV languages, where right-adjunction is often exceptional if possible at all, and in any case is of a completely different sort, in my view; see Ernst (to appear-b) for discussion). This difference is illustrated in (1-4):

(1) a. Karen has recently been buying first-aid supplies.

b. Karen has been buying first-aid supplies recently.

(2) a. Fred will often discuss this question.

b. Fred will discuss this question often.

(3) a. Karen has luckily been buying first-aid supplies.

b. *Karen has been buying first-aid supplies luckily. (no comma intonation)

(4) a. Fred will probably discuss this question.

b. *Fred will discuss this question probably. (no comma intonation)

(Some versions of current syntactic theory would deny that the postverbal adverbs are really right-adjoined. ${ }^{1}$ This issue will not matter here, since all that is crucial is the descriptive

1 See Alexiadou (1997) and Cinque (1999) for prominent examples. 
difference.) In (1-2), the adverbs recently and often may occur either between the subject and the verb, as in the a. sentences, or in final position, as in the b. sentences. But in (3-4), luckily and perhaps may only occur in preverbal position.

The first stab at a solution to the distinction between (1-2) and (3-4) might be that the adverbs in the first two sentences are functional, or quantitative, while those in the second pair are lexical, or qualitative. ${ }^{2}$ On this view, the time and frequency adverbs in (1-2) would line up with other functional adverbs in (5), while the more 'lexical' adverbs would be a subclass of predicationals, shown in (6). I put domain adverbs with predicationals for the moment, since they are similar in many ways, though they are not really of this class:

\section{(5) Functional Adverbs (not a complete list)}

(a) Frequency (broadly defined): often, occasionally, always, twice, again

(b) Location Time: today, previously, now, then, once

(c) Duration: briefly, momentarily

(d) Aspectual: still, already, yet

(e) Focusing: even, only, merely, just

(6) Predicational Adverbs

(a) Speaker-Oriented: (i) Discourse-Oriented: frankly, honestly

(ii) Evaluative: luckily, oddly, significantly, unbelievably

(iii) Epistemic: Modal: probably, perhaps, necessarily

Evidential: clearly, obviously, plainly

(b) Subject-Oriented: (i) Agent-Oriented: cleverly, tactfully, stupidly, wisely

(ii) Mental-Attitude: reluctantly, willingly, gladly, calmly

(c) Exocomparative: similarly, likewise, accordingly

(d) Pure Manner: loudly, woodenly, brightly

(e) Domain: phonologically, chemically, politically (Not predicational but similar)

Also, manner adverbs do right-adjoin, both pure manner adverbs as in (6d) and the manner versions of the other predicationals shown in (6). So the real issue concerns right-adjunction for adverbs with non-manner readings.

In this paper I will propose that the functional/predicational division is close to the mark, but that the right division is slightly different and a bit more fine-grained. One salient property of predicationals is that they all represent gradable predicates, and many nongradable adverbs indeed occur postverbally. Among other things, this means that domain adverbs, while they have sometimes been claimed to be predicational or at least 'lexical', ${ }^{3}$ are not best classified as such. As we will see, they are not gradable, and can occur to the right of the verb. Perhaps more interestingly, I will show that mental attitude adverbs are predicational, but lack one crucial semantic property which the other predicationals have, and that this frees them up to be able to adjoin to the right just like recently, often, and nongradable adverbs. In other words, I will show that there is a semantic property shared just by all the adverbs in (6) except domain and mental-attitude adverbs, which predicts the impossibility of right adjunction. The

2 Ernst (1984) calls predicationals 'Quality adverbs', and Laenzlinger (1997) similarly distinguishes 'qualitative' from 'quantitative' adverbs in a way that corresponds roughly to the $5 / 6$ distinction.

3 E.g. by Ernst (1984), chapter 2. 
point of all this is to try to zero in on precisely those semantic properties which enable us to predict important differences in the syntactic distribution of various adverbs.

I will start by providing some background assumptions about the mapping between syntax and semantics. After that, I consider and reject the obvious first guesses about the distinction between these adverbs that may adjoin to the right and those that may not. Then I will make a proposal and show how it makes the correct cut, focusing on the adverbs which represent gradable predicates yet still may right-adjoin, including mental attitude adverbs and the time-related adverbs in (1-2). I conclude with a summary and brief discussion of this result.

\section{Basic Assumptions}

As noted above, everyone assumes that at least some aspects of adverb distribution can be predicted from their semantics. The big questions are how much can be predicted, and exactly how the mapping between syntax and semantics is to be done. My view is that a lot of it can be predicted, and that the mapping ought to be as direct as possible.

Consider first the difference between location-time expressions like yesterday, now, or on Saturday, and frequency adverbs such as occasionally or frequently. Cross-linguistically, in terms of possible syntactic positions, it is clear that frequency adverbs may occur lower in structure than location-time phrases (even if there is variation among individual items, so that not all frequency adverbs may occur in low positions). This is easiest to show in SOV languages, or those like Chinese whose adjuncts follow typical OV ordering even though it is head-initial in terms of complements. (7-8) illustrate the fact that manner expressions may follow the verb in Chinese, while time and all other 'high' adjuncts, such as the epistemic adverb yiding 'definitely', may not:

(7) Heiban, xiaozhang mai de hen kuai.

blackboard principal buy DE very fast

'Blackboards, the principal bought quickly.'

(8) Xiaozhang mingtian yiding hui mai heiban (*mingtian) (*yiding).

principal tomorrow definitely will buy blackboard tomorrow definitely

'The principal will definitely buy blackboards tomorrow.'

As I have argued elsewhere, postverbal position in Chinese indicates a low adjunction site, in VP. Now observe in (9) that frequency expressions like liang $c i$ 'twice' also may occur in this position; essentially following the analysis of Soh (1998), they are in a low specifier position, over which the verb raises (details are irrelevant here):

(9) Xiaozhang hui mai liang ci heiban.

principal will buy two time blackboard

'The principal will buy blackboards twice.'

Similar evidence can be found for Japanese (see Fujita (1994)) and German (Frey \& Pittner (1999)) among other languages, and in English as well, although the evidence is weaker for the latter. (This of course involves rejection of the Larsonian/Kaynean view that time adjuncts are licensed below complements in VP-shells. For discussions of this approach, see Stroik (1990), Stroik (1996), Laenzlinger (1997), Giorgi \& Pianesi (1997), and Cinque 
(1999).) The distinction can be made to follow if we consider frequency modifiers to be 'event-internal' in some way, perhaps taking them (as does Moltmann (1997)) as defining the interior mereology of events. By contrast, location-time modifiers take a complete event and locate it at an interval in time. If only event-internal modifiers can occur low in structure, then the positional differences can be derived. Though this idea has not been formalized, as far as I know, it seems to make the right distinction, and constitutes a clear instance where a specific semantic property correlates with syntactic distribution.

Now consider a second case, involving the relative order of adverbs and modals. Here I would like to contrast my view of a fairly direct mapping between syntax and semantics with that advocated by Cinque (1999) and others, ${ }^{4}$ where the mapping is less direct. As illustrated in (10), certainly can occur on either side of deontic must, while in (11) the agent-oriented adverb cleverly can only follow it:

(10) a. The protagonist in your novel must certainly solve the mystery by herself.

b. The protagonist in your novel certainly must solve the mystery by herself.

(11) a. The protagonist in your novel must cleverly solve the mystery by herself.

b. *The protagonist in your novel cleverly must solve the mystery by herself.

On Cinque's approach, each adverb is licensed in a one-on-one relation with a specific functional head having a related meaning, and these heads are ordered by UG in a rigid clausal hierarchy. Thus for (10-11) the relevant portion of the clause would look something like (12) (the actual node labels are not important to the point):

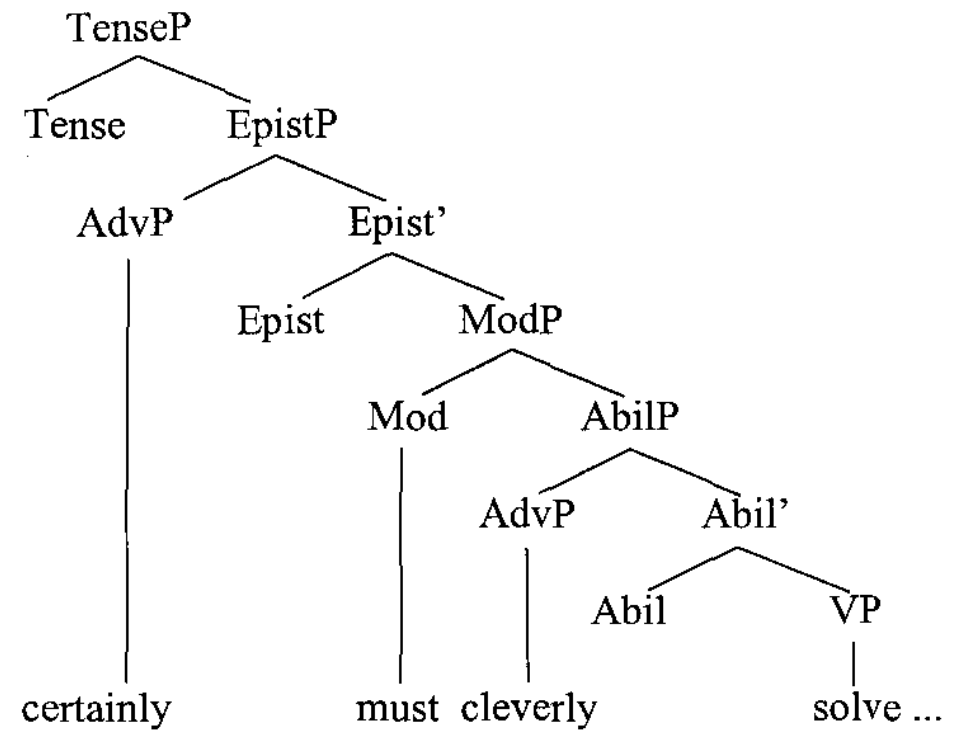

(11b) is ruled out because must starts above cleverly, and the adverb can never raise over must. But both (10a) and (10b) are all right because must can optionally raise to Tense over certainly. There are other ways to account for this sort of data on this approach, but they share the assumption of rigid ordering of adverbs, with various movements of heads around them. The relationship between syntax and semantics is indirect, because the essential property of cleverly that makes it occur below certainly is encoded in the ordering of the functional heads that license the adverbs. Once this is in place everything else is syntax.

4 E.g. Alexiadou (1997) and Laenzlinger (1997). 
By contrast, on a more direct approach one might explain (10-11) as follows. As far as syntax is concerned, adverbs are free to adjoin anywhere between the subject and verb, and must obligatorily moves to Tense, with possible adverb adjunction sites just above or below it, as shown in (13), where (a-b) show the two optional positions for each adverb:

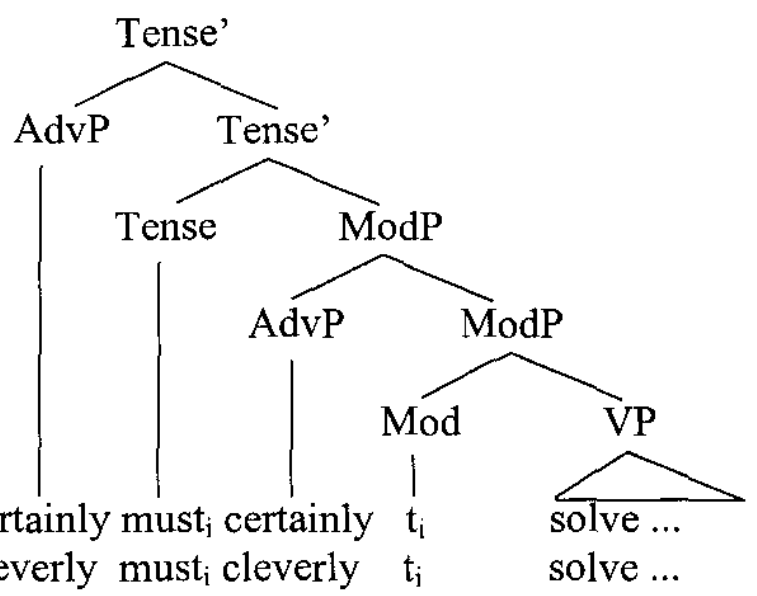

Epistemic adverbs like certainly are essentially speaker's judgments about the degree of likelihood of some proposition, so they generally may take scope over modals. This accounts for its position before must in (13a). As for the order must - certainly, if we assume that the trace of a chain may mark narrow scope, then the adverb can still take wide scope over must, since it c-commands the modal's trace..$^{5}$ As for cleverly in (13b), when it follows must it is within the modal's scope. But what about the case when it precedes, where it is ungrammatical? I take agent-oriented adverbs like cleverly as having two arguments, one being the agent which is usually the subject of the sentence, and the other being the event represented by the phrase in its immediate scope. ${ }^{6}$ Now, an important property of agentoriented adverbs is that this event must be one that the agent can control, if only to be able to choose not to do it. ${ }^{7}$ But must indicates an obligation, which cannot be controlled by the obliged entity. So this eventuality is of the wrong semantic sort to be in the scope of the adverb, and (11b) is ungrammatical.

Although I advocate precisely this analysis, my point at the moment is merely to show that this is part of a system where sentences with combinations of adverbs, modals, aspectual operators, and the like are possible only if they fit together semantically, without violating any of their scope or other semantic requirements. There are purely syntactic effects, but they are minimal. I have argued for this approach in a number of places (see Ernst (1998), Ernst (to appear-b), for example), and I believe it has advantages over the theory based on one-to-one licensing by functional heads, in particular that it captures a number of generalizations more simply and elegantly. In this paper I do not aim to present evidence to distinguish the two approaches, but my main goal is to continue to identify the semantic properties which correlate with aspects of syntactic distribution, so that we eventually can see more clearly which theory does a better job in capturing these generalizations.

5 See Ernst (1991), Aoun \& Li (1993), and Ernst (to appear-b) for discussion.

6 See Ernst (to appear-b) for discussion and justification.

7 I use the term event in the loose, syntactician's sense more often rendered as eventuality in the semantic literature, encompassing processes and states as well as actions. On the 'controllability' requirement, see the discussion in Ernst (1984), chapter 2. 


\section{Predicational vs. functional adverbs}

\subsection{Predicational adverbs}

Predicational adverbs, listed in (6), are those which have the properties in (14):

(14) Typical properties of English predicational adverbs:

(a) come from open classes

(b) are composed of an adverb stem and -ly

(c) take a proposition, fact, or event as one of their arguments

(d) show the clausal/manner pattern of 'homonymous' readings in most cases

Clausal readings (often called "sentential"8) are shown in the a. sentences of (15-19):9

(15) a. Frankly, they won't speak to her.

b. They won't speak to her frankly.

(16) a. Clearly, they saw the sign.

b. They saw the sign clearly.

(17) a. Strangely, Nikki was holding it.

b. Nikki was holding it strangely.

(18) a. Intelligently, Carol explained it.

b. Carol explained it intelligently.

(19) a. Accordingly, they adjusted the angle.

b. They adjusted the angle accordingly.

Not all types of predicationals show this split; modal and pure-manner adverbs are restricted to clausal and manner readings, respectively, as illustrated in (20-21):

(20) a. They probably have been playing Stairway to Heaven.

b. *They have been playing Stairway to Heaven probably.

(21) a. *They loudly have been playing Stairway to Heaven.

b. They have been playing Stairway to Heaven loudly.

But since this restriction can be explained independently (see Ernst (1987)), I take the existence of the dual-reading pattern as a defining feature of the predicational class.

8 See Ernst (to appear-a), Ernst (to appear-b) for further detail.

9 Clausal predicational adverbs, essentially divide into three types, according to scope. The first, 'DiscourseOriented', is sometimes known as 'Pragmatic' or 'Speech-Act' adverbs (see Bellert (1977), Mittwoch (1976)). The second corresponds to the rest of the 'Speaker-Oriented' group in Jackendoff (1972), which includes the Discourse-Oriented subclass, and to 'Ad-S' for McConnell-Ginet (1982) (narrowly speaking, it is this group that is probably best termed 'sentential'). The third, for which I follow Jackendoff's 'Subject-Oriented', is 'Ad-VP' for McConnell-Ginet. 
I assume that the manner adverbs in (15-19 b) are adjoined to the right in VP, so the discussion about how predicational and functional adverbs differ with respect to rightadjunction is really an issue of why most predicationals cannot adjoin high and to the right, attached to functional projections above the basic VP, with clausal readings. In addition to the examples in (1-4), we may add those in (22) for functionals, which do adjoin high and to the right, and (23-25) for predicationals, which do not (again, as always, we must exclude comma intonation):

(22) a. She didn't fall asleep right then.

b. The visitors didn't understand us momentarily.

c. Paul was wearing the hat already.

d. Christine will go swimming again.

(23) a. Frankly, Dan is way ahead of his classmates.

b. *Dan is way ahead of his classmates frankly.

(24) a. The committee will wisely remain neutral on this issue.

b. *The committee will remain neutral on this issue wisely.

(25) a. Similarly, no theory exists in a vacuum.

b. *No theory exists in a vacuum similarly.
(Location-Time)

(Duration)

(Aspect)

(Additive)

(Discourse-Oriented)

(Agent-Oriented)

(Exocomparative)

While the (b)-sentences in (23-25) are marginally possible with manner readings, they are certainly out with the intended clausal readings. The (a)-versions are fine, with preverbal, non-manner readings.

There is good evidence in all these cases that these postverbal adverbs are adjoined high and to the right. Even in analyses following the antisymmetric (Kayne (1994)) approach like Cinque's, where right adjunction is banned in principle, various raising operations result in the effect of right-adjunction, so the evidence is still valid for the 'surface' structure (at SpellOut) in such theories. We already saw above that there is good evidence for location time adjuncts, like right then in (22), being above the lexical VP. The fact that such adverbs can optionally take scope over negation confirms the possibility of high right adjunction, as in (26); imagine a case where last week, for the second week (time), a carousing man did not come home on two different nights:

(26) He didn't come home twice again last week.

The same sort of test can be used for (22b); here momentarily takes scope over didn't understand us; as usual I assume that scope is mediated by c-command (except for cases of 'chain-scope' as discussed above for (13), which does not apply here since negation does not raise). This conclusion is strengthened by sentences like (27):

(27) They didn't understand us out of fear momentarily, but even after they calmed down they were still somewhat thrown off by our accents.

Imagine that we are fearsome-looking tourists, and we startle some natives when we come around the corner. For a moment they are afraid and cannot process what we are saying, so that momentarily, out of fear, they don't understand us. Here the duration expression takes 
scope over the causal phrase out of fear, which in turn takes scope over negation. Finally, proform substitution in (28), based on (27), confirms the relevant constituent structure:

(28) They didn't understand us out of fear momentarily, and then did so because of our accents for another few minutes.

In (28) do so is interpreted as didn't understand $u s$, so the causal phrase and the duration phrase c-command negation.

The same sorts of tests work for already and again. In (29), already takes scope over obeying her out of love, and on the usual assumption that a reason-phrase like out of love is relatively high in structure, then already should be even higher. This is confirmed by the constituency evidence from do so in the parenthesis:

(29) Fido was obeying her out of love already, instead of fear (but Rex was not doing so yet).

And in (30a-b), taking the phrases on Saturday and because Jim asked her to be outside the lexical VP, again should be higher (where it modifies go swimming, not ask):

(30) a. Christine will go swimming on Saturday again.

b. Christine will go swimming because Jim asked her to again.

It should be noted that these wide-scope readings for postverbal adjuncts are often disfavored, but this does not mean that they cannot occur. In fact, often all that is needed to make the wide-scope reading normal is to adjust the discourse structure so that the preceding material is old information. I will assume that the differences in position can be linked to information structure, but that this has no effect on the syntax and on the possibility for wide scope readings.

Given all these results, the pattern we must account for is shown schematically in (31) for different adverbial classes, where IP stands in for all functional projections above the minimal VP, including those headed by any elements of the 'split Infl', negation, auxiliary verbs, and the like: 10

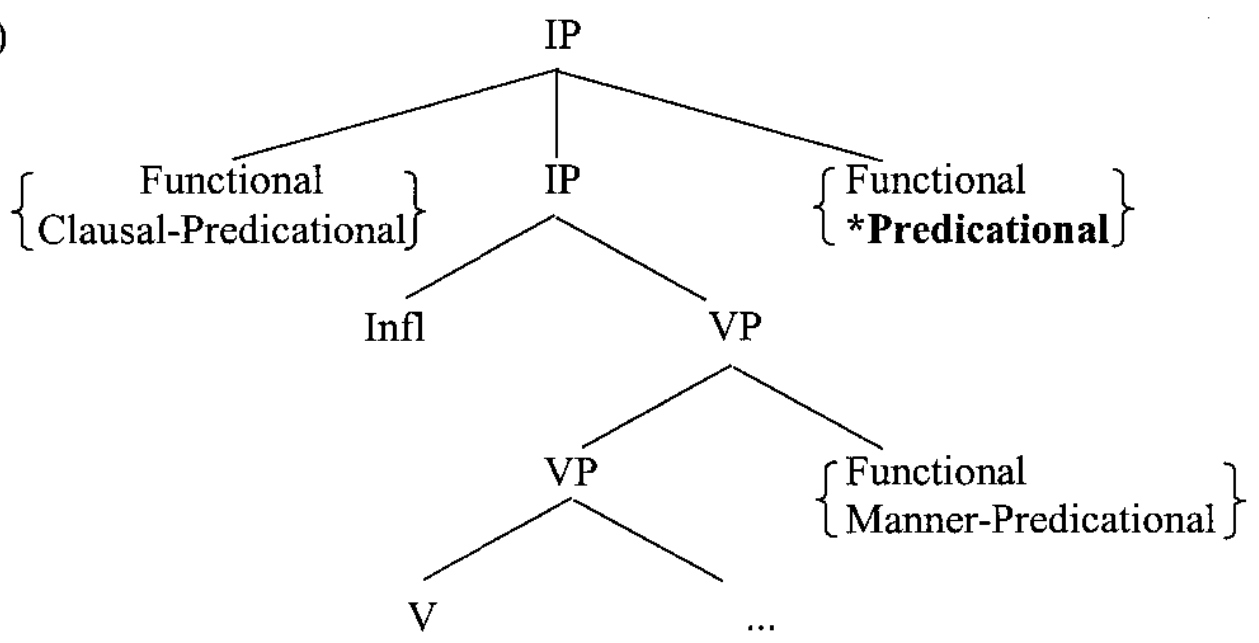

$10 \mathrm{I}$ assume that left-adjunction in VP in VO languages is excluded independently. I also assume that the lexical verb obligatorily moves into the head of the lowest functional projection, Pred. Neither assumption affects the arguments discussed here. See Ernst (to appear 1999), Ernst (to appear-b) for details. 


\subsection{What semantic property is relevant?}

\subsubsection{Open vs. closed classes?}

There are a number of possible ways to distinguish predicational and functional adverbs that might distinguish correctly between those which can right-adjoin to functional projections and those which cannot. Consider first the open-class/closed-class distinction. Certainly, the temporal, aspectual, focusing, and quantificational adverbs listed in (5) come from limited, closed classes of adverbs, while predicational adverbs like oddly, clearly, frankly, or softly belong to open classes. But this runs into two problems. First, if we want a theory of adverb syntax to be embedded in a larger theory of adverbials, i.e. verbal and sentential modifiers, then we could not easily extend this explanation to the open class of temporal and frequency adjuncts like $a$ week ago, on the First Tuesday in April, or twenty-seven times, which is quite productive. Second, and more importantly, some predicational adverbs have closed classes and some open-class adverbs may right-adjoin to functional projections. The first case, of a closed class of predicational adverbs, is represented by modal adverbs, whose members number only a handful, those in (32) and perhaps a few more:

(32) Modal adverbs:

maybe, probably, possibly, perhaps, necessarily, definitely, indubitably, ...

The second is domain adverbs, with a sample given in (33). Whether they should be classified as predicational or not, they clearly come from an open class, since new domains of endeavor can always be invented, and practically any technical distinction in any field of study may be used as a domain adverb; (34) provides an example of this from linguistics, where sloppy identity in ellipsis is being contrasted with strict identity:

(33) logically, mathematically, choreographically, chemically, nautically, botanically, ...

(34) "The ellipsis in (85) can be understood sloppily, ..." (Fiengo \& May (1994), p. 125)

As (35a-b) demonstrate, domain adverbs may right-adjoin to functional projections, assuming again that postverbal adjuncts adjoin upward successively to the right, and that location-time adverbs are adjoined hierarchically above VP:

(35) a. They have worked hard since then politically.

b. The company's productions have improved this year vocally, if not instrumentally.

Thus the difference we are looking for does not seem to be open versus closed classes.

Before going on to a second possible solution, I must mention focusing adverbs, some of which do not adjoin to the right. These are exemplified in (36); as always, I exclude comma intonation, or 'afterthought' intonation:

(36) a. The horses \{just/merely\} ran a mile.

b. ${ }^{*}$ The horses ran a mile $\{$ just/merely\}.

Some other members of this class do sometimes adjoin rightward, as in (37), though speakers vary in their acceptance of these sentences, and they are somewhat restricted prosodically. This indicates that as a class they may right-adjoin at least in principle: 
a. The horses $\{$ even/only\} ran a mile.

b. The horses ran a mile $\{$ even/only\}.

I have argued elsewhere (Ernst (to appear 1999), Ernst (to appear-b)) that these adverbs belong to a class of 'Lite' adverbs (morphologically 'deficient' in the terms of Cardinaletti \& Starke (1996)). Such adverbs are usually barred from postverbal positions, and most of the time are also barred from sentence-initial position, as in (38):

* $\{$ Just/Merely/Even/Only $\}$ the horses ran a mile.

Although the string of words in (38) is in fact grammatical, this is true only if the adverbs are part of the subject. With the adverbs taking scope over the whole sentence, parallel to (35a), (36) is ungrammatical. Thus there is evidence for a PF-based, morphological explanation for the restriction on right-adjunction for these adverbs, which may be marked on individual adverbs, and we need not consider them in our semantic deliberations (see Ernst (to appear-b) for detailed discussion).

\subsubsection{Quantitative vs. Qualitative?}

Returning to the split between free and forbidden right-adjunction, one might try to take the idea of quantitative vs. qualitative adverb semantics seriously, treating functional adverbs as quantificational and predicational adverbs as qualitative. But again, time and domain adverbs do not fit: time adverbs are not necessarily quantificational, and domain adverbs are certainly not; both can right adjoin, as shown earlier.

\subsubsection{Gradable vs. Nongradable?}

Perhaps it is a matter of gradability - certainly location-time expressions like yesterday and now are not gradable; neither are domain adverbs. Observe (39-40):

(39) a. Politically, they have worked hard since then.

b. They have worked hard since then politically.

(40) a. Very politically, they have worked hard since then.

b. They have worked hard since then very politically.

Although politically appears to be able to take a degree modifier, when it does so as in (40) it is no longer a domain adverb; rather, it is agent-oriented, like craftily or ambitiously, making an evaluation of the agent on the basis of what he or she does. That is, the speaker is judging an agent as being very motivated by politics, rather than, in (39), saying that their working hard is evaluated in the political arena (as opposed to academics, or the theater, or weightlifting).

So we might try to say that these non-gradable adverbs may right-adjoin, while the predicational adverbs, which are gradable, may not. But this, too, fails, because there are obviously functional adverbs which are gradable and also right-adjoin. These include some location-time adverbs like recently, some duration adverbs such as briefly and momentarily, and most frequency adverbs. Examples are shown in (41), the adverbs being both degreemodified and right-adjoined; their position to the right of purpose or causal expressions shows their high adjunction site: 
(41) a. Carol has robbed drugstores to get drugs more recently than Kim.

b. Alice drank whiskey because Jim did only very briefly.

c. Mark went to the gym to increase his strength quite often.

More seriously, there is another open-class group which has always been assumed to be predicational, yet also seems to adjoin high and to the right: mental attitude adverbs like reluctantly, willingly, and anxiously. Observe the sentences in (42-44):

(42) a. Mark willingly rode a bicycle on the day of the transit strike.

b. Mark rode a bicycle on the day of the transit strike willingly.

(43) a. I will gladly pay you on Tuesday.

b. I will pay you on Tuesday gladly.

(44) a. Tori reluctantly had stopped dancing for a month.

b. Tori had stopped dancing for a month reluctantly.

Since this group of adverbs will end up being rather important to my argument, it will be useful to spend a bit more time making sure that they really do adjoin to the right above the minimalVP. Recall that it is a general pattern for predicational adverbs that they have clausal readings above VP, but manner readings within VP. With mental attitude adverbs the clausal/manner distinction is not as clear as for, say, agent-oriented or evaluative adverbs (like wisely or strangely). But it comes out in (45):

(45) a. She \{reluctantly/willingly\} had waited for him.

b. She waited for him \{reluctantly/willingly\}.

(45a) seems better with an interpretation where her willingness or reluctance is about whether to wait or not to wait, while (45b) seems more felicitious when taken as indicating her mental attitude during the wait, but might also have the reading in (45a). This is as expected, since in (45b) the adverb could be right-adjoined to the minimal VP, giving the manner reading, or above VP, for the clausal reading; in (45a) only the clausal reading is possible, since the adverb is to the left of an auxiliary verb, and therefore outside the minimal VP.

I have tried to show that the gradable vs. nongradable distinction does not get the distinction we are looking for. Nevertheless, I think that gradability is useful as the first cut: we can say that if an adverb is not gradable, then it may adjoin high and to the right. This accounts for the domain adverbs and many of the functional adverbs, at least, as shown in the top part of the chart in (46):

PREDICTIONS

a. Nongradable Adverbs that

Can High Right-Adjoin

Domain

Aspectual

Some frequency

(Most) duration

(Most) location-time

Focusing

\section{EXCEPTIONS}

Nongradable Adverbs that

Cannot High Right-Adjoin 


\author{
PREDICTIONS \\ b. Gradable adverbs that \\ Cannot High Right-Adjoin \\ Speaker-Oriented \\ Agent-Oriented \\ Exocomparative \\ Manner
}

\author{
EXCEPTIONS \\ Gradable adverbs that \\ Can High Right-Adjoin \\ Many frequency \\ Some duration \\ Some location-time \\ Mental Attitude
}

If this is on the right track, then we must concentrate on seeing what it is that the gradable adverbs in the lower left quadrant have in common that all the others do not. I turn to this in the next section.

\section{A Proposal}

\section{1. "Subjective" Adverbs}

I suggest that the restricted adverbs, the ones which may not right-adjoin to functional projections, are those gradable predicates which are "subjective":

(I) Adverbs may not right-adjoin to functional projections if they are "SUBJECTIVE".

(II) "Subjective" adverbs are (a) gradable adverbs, (b) on whose scale the members of its comparison class (event/proposition) may be (re)ranked according to the speaker's judgment of the context.

Obviously, (II) will take some explaining. I use the term "subjective" impressionistically and tentatively. I intend it to reflect the speaker's making a judgment about the event or proposition in context - for example, how likely it is, for a modal adverb like probably; how advantageous it is, for an evaluative adverb like luckily; or how well it supports calling an agent stupid or tactful, for the agent-oriented adverbs stupidly and tactfully. What is most subjective about this is that the context can easily change the way the judgment is applied, causing a rearrangement of items on the scale. This more or less subjective judgment contrasts with the functional adverbs, where the way in which one maps events or propositions onto a time, frequency, or duration scale is much less changeable with the context.

\subsection{Scales, Norms, and Comparison Classes}

I adopt a common view of gradable predicates (Bierwisch (1989), Kennedy (1999)), whereby gradable adverbs represent predicates of adjectival form, which are measure functions mapping the event or propositional argument onto the appropriate scale, such as probability, intelligence, similarity, closeness in time, frequency, and so on. As with any case of gradable semantics, the interpretation needs a comparison class determined by some combination of context and the nature of the objects being mapped onto the scale. In simple cases, like (47), the comparison class might be all women, so that she is clever for a woman; or it could be all people, so that she is clever for a person, and also happens to be a woman: ${ }^{11}$

She is a clever woman.

11 Cf. the discussion of extensional and intensional ways of determining comparison clases in Bierwisch (1989), p. $119 \mathrm{ff}$. 
The comparison class plays the major role in determining the standard, or norm. Often the norm can be taken as an average for members of the comparison class. ${ }^{12}$ This means that a shift in the comparison class may bring a shift in where the norm is on the scale. For (48), for example, if Karen is five years old, and she is judged as a member of the class of 5-year-olds, the norm $\mathrm{N}_{\mathrm{C}}$ for well will be low on the scale; but if she is judged on the scale for all people, including adults, the norm will obviously be much higher:

(48) Karen dances well.

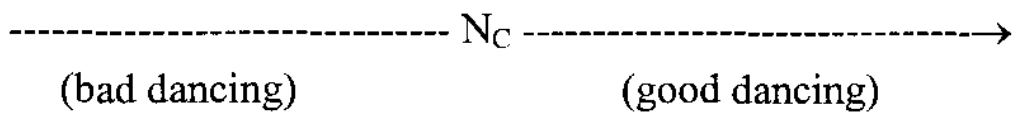

Finally, gradable predicates may be more or less (in)determinate (or 'non-linear'; see the discussion in Kennedy (1999), p. 13), that is, they may be restricted to one or a very few dimensions, as in the case of a color term like purple, or be quite broad, such as important, good, or big. An object can be good or important in many different ways or for many different purposes, and in fact can be good in one dimension (say, for drinking) but bad in another (as for washing clothes). Likewise for big, where a film can be big at the box office but decidedly not big with the critics. Importantly, indeterminacy is what allows for reranking of objects in the comparison class. Take the class of writers, for a simple example, in (50-51):

(50) This writer is \{economically/intellectually\} important.
a. Stephen King > Thomas Mann > Albert Einstein
(economically)
b. Albert Einstein $>$ Thomas Mann $>$ Stephen King
(intellectually)

I suppose that the popular American writer Stephen King makes much more money than did Thomas Mann, who in turn made more money from his books than Albert Einstein (51a), but in terms of intellectual impact the ranking is presumably reversed (51b).

It is unclear to me whether one ought to treat every predicate as establishing a unique ordering of elements in the comparison class, in which case these examples would technically involve different, homophonous gradable predicates, each with a different, contextually determined 'dimension', or instead we should give up the idea that the ordering is determined solely by the comparison class, and say that a given class may have different rankings for different contexts. Since my main interest here is descriptive, I will take the latter tack, but nothing of importance here is lost with the first option.

\subsection{Gradable "Subjective" Adverbs}

Turning to an adverbial example in (52), imagine a very gregarious and uninhibited woman Lorraine, who normally would never leave a party before four in the morning:

(52) Surprisingly, Lorraine left the party early.

(53) a. Leave early $>$ Sit quietly in the corner $>$ Talk to many people $>$ Dance on the table

b. Dance on the table $>$ Talk to many people $>$ Sit quietly in the corner $>$ Leave early

12 Norms may also be established via prototypes; cf. Bierwisch (1989), p. 119. 
Surprisingly is an evaluative adverb which (in effect) has a comparison class made up of states of affairs in a given context. ${ }^{13}$ In this case, (53a) might be the relevant ranking on the scale of 'surprisingness' of such states of affairs - loosely, things she might have done at the party - in which leaving early is the least likely, and thus the most surprising. But suppose the context changes, and Lorraine is ill, or she is trying to be more demure as an experiment. Now the same comparison class might be reversed, as in (53b), so that one would say not (52) but (54):

(54) Surprisingly, Lorraine danced on the table.

Consider a second example, with agent-oriented adverbs like wisely, stupidly, and graciously, with the example in (55):

\section{Intelligently, Bob went to Los Angeles.}

I take adverbs of this sort to evaluate an event in terms of how one would judge the agent for doing it in context. Suppose that Bob is an stage actor in Boston, and wants to launch his film career. The ranking of events - things he might do - could reasonably be as in (56a), considering that New York is a better place than Boston for a film actor, but not as good as Los Angeles:
(56)
a. Go to Los Angeles $>$ Go to New York $>$ Stay in Boston
b. Stay in Boston $>$ Go to New York $>$ Go to Los Angeles

On the other hand, if Bob will get a million-dollar inheritance if he takes his rich Bostonian aunt's dogs out walking once a week, so that staying in Boston is his best option, then the ranking might be reversed as in (56b), with (55) becoming false or infelicitous.

Similar scenarios can easily be constructed for the other types of predicational adverbs, such as probably, similarly, or obviously. In all of these cases, when the context changes, the speaker is free to rerank the objects in the comparison class. Note especially that this is true even for modal adverbs, which have a scale that is fairly restricted dimensionally, i.e. a scale of probability that the proposition in question is true. What matters is that as the context changes, the ranking of the states of affairs (propositions) may change.

\subsection{Gradable Functional Adverbs}

The situation is different for the gradable functional adverbs we looked at briefly above, listed again here as the exceptions on the right side of (46b):

$$
\text { PREDICTIONS }
$$

b. Gradable adverbs that

Cannot High Right-Adjoin

Speaker-Oriented

Agent-Oriented

Exocomparative

Manner

\author{
EXCEPTIONS \\ Gradable adverbs that \\ Can High Right-Adjoin \\ Many frequency \\ Some duration \\ Some location-time \\ Mental Attitude
}

\footnotetext{
13 Actually, I and others treat evaluative adverbs of this sort as taking facts ( = true propositions) as their single argument. But the distinction between facts and states of affairs does not matter here; any state of affairs, speaking loosely, can be what a fact 'is about'.
} 
Examine the sample sentences in (57-59):

(57) a. Megan goes dancing pretty often.

b. Terry drives to Philadelphia frequently.

(58) They left the ice cream out on the table briefly.

(59) a. The comet will return soon.

b. Paul will be home from school soon.

All three of these types of adverbs map events onto a scale directly derived from time scale, with degrees representing time intervals. In the simplest case, soon in (59) involves the short length of time between speech time, presumably now, and a future event time. The higher an event is on a scale of 'soonness', the closer it is to speech time:

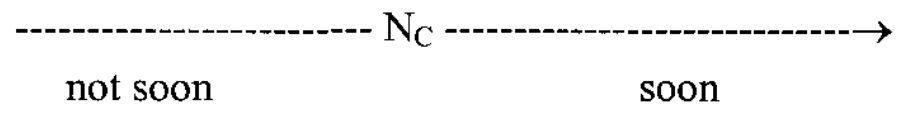

The standard or norm $\mathrm{N}_{\mathrm{C}}$ is determined in part by the events in question, i.e. the comparison class. The actual time period for a comet's returning soon, by astronomical standards, might be stated in terms of decades, while the time period for a child returning from school soon would be in minutes. The scale stays the same, with only the time interval chosen as the norm changing. With the same sentence, slightly different comparison classes may be chosen; so, for example, if a comet returns in 20 years this might be considered soon for a comet, but if the comparison class is composed of observable celestial objects it would not, since the moon, satellites, and planets come and go much more often. So the norm for recurrence of all the things you can see in the night sky is much lower on the scale than it is for the recurrence of comets.

Now consider ways in which a different norm might be chosen in (59b), for exactly the same comparison class, that of a child coming home from school. If the school is three blocks away and the child walks home at 3 PM every day, it would be odd to say (59b) at noon on Thursday, since at noon, 3 PM is a fairly long time off in the context of a school day. But if the child is at a boarding school and regularly comes home on Fridays, the sentence becomes felicitous. Now imagine the boarding-school scenario, but where someone calls on the phone at noon on Thursday, wanting to talk to Paul, and asking if she should call back a bit later. Now Paul's parent might utter (61):

(61) No, Paul isn't going to be home soon -- he won't be home until tomorrow night.

In the context of calling back later, the norm for soon is lower on the scale than it is for a normal weekly return home from boarding school, even though the comparison class is the same: events of Paul returning home from boarding school.

Now note that, crucially, even though context plays a role in determining the norm on the scale, there is no reranking of events on this scale, because they are necessarily ranked according to a rigidly linear time-line. In (62), the times of various possible events of Paul returning home, regardless of where the norm is placed, will always have the same ranking:

(62) 1 PM Thursday $>3$ PM Thursday $>10$ AM Friday $>8$ PM Friday 
The same is true for the gradable frequency and duration adverbs in (57-58). Regardless of the precise analysis of frequency adverbs we pick (see the proposals and references in Vlach (1993), de Swart (1993), and Moltmann (1997)), frequency is agreed to involve some sort of ratio of numbers of events to intervals, and duration modifiers (Vlach (1993), Kamp \& Reyle (1993)) provide the length of a time interval. So for the same reason, events in the comparison class of sentences like these cannot be reranked: any more frequent or longer-lasting event will always be higher on a scale than a less frequent or shorter one, regardless of the context or where the contextual norm is placed on the scale.

\subsection{Mental Attitude Adverbs}

To sum up what we have so far, most predicational adverbs are "subjective" as defined in (II) because the members of the comparison class may be reranked in different contexts, while for gradable functional adverbs there in no possibility of reranking. The last remaining exception to the generalization about high right adjunction is the mental attitude subclass of predicationals, including willingly, calmly, eagerly, reluctantly, and gladly.

The crucial difference between mental attitude adverbs and all the other predicationals is that they do not map their event argument onto a scale of willingness, calm, reluctance, and so on. In (63a), for example, the event of Tori flying to Paris is not willing; instead, Tori is willing, and in (63b) it is Bob who is reluctant, not the event of his playing a waltz:
a. Tori willingly flew to Paris.
b. Bob reluctantly played another waltz.

In other words, the comparison class is experiencers, mapped onto the scale of degrees of some mental state according to the norm for people (or for whatever entity has the mental state). Of course, the adverbs do take an event argument in the sense that the mental attitude is 'with respect to' or 'about' the event. But the comparison class, which determines the norm along with context, is experiencers of the mental attitude - unlike agent-oriented adverbs, for example, which map their event argument onto a scale according to how it reflects on an agent argument in terms of cleverness, wisdom, stupidity, or the like.

This can be seen more clearly in the overt comparative, which, following the majority view (see Bierwisch (1989), Kennedy (1999), and references therein), has the same basic semantics as the absolute (positive) constructions (which are essentially covert comparatives):

(64) a. Tori flew to Paris more willingly than Christine.

b. Bob played another waltz more reluctantly than Barbara.

What is being compared in these two sentences is the experiencers' degrees of willingness or reluctance, which does not necessarily have anything to do with the events themsclves. It might be, for example, that Christine is depressive and is not willing to do anything at all. We must be careful not to be sidetracked by the fact that different contexts, including different events, may affect the actual degree of the mental attitude in question. Observe (65):

(65) a. Calmly, Carol stood at the edge of the cliff with the rampaging herd behind her.

b. Calmly, Carol waited for the bus.

Here, presumably, Carol will be calmer waiting for the bus than when in danger of being pushed over a cliff. But still, it is Carol that is calm, not the event, and the norm for calmness is set by a comparison class of people, not of events. 


\section{Conclusion}

\subsection{Summary}

I have suggested that the semantic property which determines whether an adverb is barred from adjoining to the right is that of being "subjective", as defined in (II):

(I) Adverbs may not right-adjoin to functional projections if they are "SUBJECTIVE".

(II) "Subjective" adverbs are (a) gradable adverbs, (b) on whose scale the members of its comparison class (event/proposition) may be (re)ranked according to the speaker's judgment of the context.

Keeping in mind that some 'Lite' adverbs are independently forbidden from adjoining high and to the right, I predicts than any nongradable adverb is able to do so, those listed in the top half of (46), given again here:

\section{PREDICTIONS}

a. Nongradable Adverbs that

Can High Right-Adjoin

Domain

Aspectual

Some frequency

(Most) duration

(Most) location-time

Focusing

b. Gradable adverbs that

Cannot High Right-Adjoin

Speaker-Oriented

Agent-Oriented

Exocomparative

Manner

\section{EXCEPTIONS}

Nongradable Adverbs that

Cannot High Right-Adjoin

\author{
Gradable adverbs that \\ Can High Right-Adjoin \\ Many frequency \\ Some duration \\ Some location-time \\ Mental Attitude
}

What we have seen is that among the gradable adverbs, those which can adjoin to the right in functional projections are of two types. Either their interpretation is crucially tied to a time line, whose intervals cannot be reordered (frequency, duration, and location time), or they do not use their event argument as the comparison class (mental attitude). Thus we have succeeded in linking a particular syntactic property to a lexical semantic property, in accordance with the general program of predicting as much as possible of adverb syntax from the independently needed semantics of the lexical items involved.

\subsection{What is "Subjective"?}

What is it about the "subjective" adverbs that allows the members of their comparison class to be reranked? It seems to be a matter of an extreme degree of indeterminateness: the predicate is relatively unspecified for some particular dimension, such as height, width, distance, color, heat, loudness, or duration of a time interval. Context does supply a 'dimension' when we use a predicational adverb, but there are no standard names for such dimensions, because they are in fact the extremely varied and contextually-dependent criteria 
for strangeness, stupidity, similarity, intelligence, and so on - involving human behavior and expectations about the world. Consider (66):

(66) a. Epistemic:

Speaker judges likelihood that $\mathrm{P}$ is true based on how the realworld situation, or source of knowledge, affects the likelihood that the corresponding event occurred.

(ex: probably)

b. Evaluative: Speaker evaluates a fact according to its effect on the speaker or other beings.

(ex: oddly)

c. Agent-Oriented: Speaker judges the agent according to how the agent's decision to enter into the event or not, given the real-world context, reflects some personal qualitiy

(ex: rudely)

d. Exocomparative: Speaker judges how similar or different two propositions or events are.

(ex: similarly)

Predicates from (66a-c) essentially require the speaker to rank propositions, facts, or events differently according to different criteria. Rudeness depends on very complex social rules; the oddness of an event depends on expectations of what is normal in a given context; judging probability likewise requires knowledge of normal and abnormal situations, cause and effect, and so on. Exocomparatives, in (d), involve judging degrees of similarity, but as anyone familiar with metaphor knows, similarity also can be evaluated according to complex and varied criteria. None of these predicates is tied down to a particular dimension in space or time observable in some direct way. Instead, they embody relatively abstract evaluations, only indirectly connected to observable dimensions.

\subsection{Conclusion}

Thus, to conclude, I have proposed that we can correlate one aspect of the distribution of adverbs with a particular semantic property. The property is that of being a "subjective" adverb, one which maps an event or proposition onto a scale with the high degree of indeterminacy and context-dependence just discussed. Such adverbs cannot adjoin to the right in functional projections, while other adverbs may. Regardless of how this correlation is to be expressed in syntactic theory, we have more evidence that aspects of adverb distribution can be directly predicted by specific semantic properties of the adverbs.

\section{References}

Alexiadou, A. (1997): Adverb Placement. Amsterdam: John Benjamins.

Aoun, J., \& Li, A. (1993): The Syntax of Scope. Cambridge, MA: MIT Press.

Bellert, I. (1977): On Semantic and Distributional Properties of Sentential Adverbs. Linguistic Inquiry 8/, 337350.

Bierwisch, M. (1989): The Semantics of Gradation. In M. Bierwisch \& E. Lang (eds.), Dimensional Adjectives, 71-261. Berlin: Springer.

Cardinaletti, A., \& Starke, M. (1996): Deficient Pronouns: A View from Germanic. In H. Thráinsson, S. Epstein, \& S. Peter (eds.), Studies in Comparative German Syntax, Vol. 2, 21-65. Dordrecht: Kluwer.

Cinque, G. (1999): Adverbs and Functional Heads: a Cross-Linguistic Perspective. Oxford: Oxford University Press.

de Swart, H. (1993): Adverbs of Quantification: A Generalized Quantifier Approach. New York: Garland.

Ernst, T. (1984): Towards an Integrated Theory of Adverb Position in English. Bloomington, IN: IULC. (1987): Why Epistemic and Manner Modifications are Exceptional, Proceedings of the 13th Annual Meeting of the Berkeley Linguistics Society. Berkeley: Berkeley Linguistics Society.

(1991): On the Scope Principle. Linguistric Inquiry 22/4, 750-756.

- (1998): Scope Based Adjunct Licensing, NELS 28, Vol. 28. Amherst: GLSA. 
- $\quad$ (to appear-a): Manners and Events. In C. Tenny \& J. Pustejovsky (eds.), Events as Grammatical Objects, Stanford: CSLI.

- $\quad$ (to appear-b): The Syntax of Adjuncts. Cambridge: Cambridge University Press.

- (to appear 1999): Adjuncts, the Universal Base, and Word Order Typology, NELS 29. Amherst, MA: GLSA.

Fiengo, R., \& May, R. (1994): Indices and Identity. Cambridge, MA: MIT Press.

Frey, W., \& Pittner, K. (1999): Zur Positionierung der Adverbiale im deutschen Mittelfeld (On the Positioning of Adverbials in the German Middle Field). Linguistische Berichte .

Fujita, N. (1994): On the Nature of Modification: A Study of Floating Quantifiers and Related Constructions. Unpublished unpublished Ph.D. dissertation, University of Rochester, Rochester, N.Y.

Giorgi, A., \& Pianesi, F. (1997): Tense and Aspect: From Semantics to Morphosyntax. Oxford: Oxford University Press.

Jackendoff, R. (1972): Semantic Interpretation in Generative Grammar. Cambridge, MA: MIT Press.

Kamp, H., \& Reyle, U. (1993): From Discourse to Logic. Dordrecht: Kluwer.

Kayne, R. (1994): The Antisymmetry of Syntax. Cambridge, MA: MIT Press.

Kennedy, C. (1999): Projecting the Adjective. New York: Garland.

Laenzlinger, C. (1997): Comparative Studies in Word Order Variation. Unpublished doctoral dissertation, University de Geneve, Geneve.

McConnell-Ginet, S. (1982): Adverbs and Logical Form: A Linguistically Realistic Theory. Language 58/1, 144184.

Mittwoch, A. (1976): How to Refer to One's Own Words: Speech-Act Modifying Adverbials and the Performative Analysis. Journal of Linguistics 13/2, 177-189.

Moltmann, F. (1997): Parts and Wholes in Semantics. Oxford: Oxford University Press.

Soh, H. L. (1998): Object Scrambling in Chinese. Unpublished Ph.D. dissertation, MIT.

Stroik, T. (1990): Adverbs as V-Sisters. Linguistic Inquiry 21/, 654-661.

(1996): Minimalism, Scope, and VP Structure. Thousand Oaks: Sage Publications.

Vlach, F. (1993): Temporal Adverbials, Tenses, and the Perfect. Linguistics and Philosophy 16/, 231-283. 